\title{
Proficiência program-nursing continuing education courses: e-learning tool
}

\begin{abstract}
Background: Proficiencia is the name of a continuing education program from the Brazilian Federal Nursing Council. Designed for nurses, nursing technicians and auxiliaries, the program offers a range of 24 free courses with 30-hour workload training and available at online learning, providing nursing practitioners an opportunity to keep up to date and develop professionally with the use of the Internet and computer. Jornada is the e-learning platform for the program. A privately owned web system officially recognized, by the Ministry of Education in 2008, as an innovative technology in encouraging educational improvements and resulting in joining the Brazilian Educational Technology Guide.
\end{abstract}

Aim: This research aimed to evaluate the effectiveness of the Proficiência Program with the usability of the e-learning platform Jornada in continuing education in Brazil.

Method: Evaluation research of the program carried out in 2013 and data was collected from the Jornada Platform database the e-learning + Learning Management System.

Results: It was found that the program had user acceptance. The results also showed that approved courses' contents and recommended and acknowledged the program as a learning tool linked to continuing education in nursing. Concluding that, the platform Jornada has enabled an online and interactive communication between students and tutors.

Limitations: Research was restricted to database information of graduated students only, omitting all data from those that didn't finish their courses.

Conclusion: Collectively, courses have provided meaningful learning for nursing practitioners, with improvements of knowledge and the ability to develop safer nursing practices

Implications for nursing and health policy

i. E-learning strategies are needed to create opportunities nursing professionals who live and work in remote areas to study and improve themselves.

ii. E-learning programs are flexible on the platform, scheduling module, study methods, accessibility, usability and support, usability and support.

iii. Training program of theoretical skill assist in the improvement of nursing quality. Nursing training policies received large contribution as a result of the program organization and construction.

Keywords: continuing education, education and teaching, learning styles, information technology, telenursing
Volume 3 Issue I - 2017

\section{David Lopes Neto,' Llapa-Rodriguez EO, ${ }^{2}$ Silva $\mathrm{MCN},{ }^{3}$ Freire $\mathrm{N}^{4}$ \\ IManaus School of Nursing, Amazonas Federal University, Brazil ${ }^{2}$ Department of Nursing, Sergipe Federal University, Brazil \\ ${ }^{3}$ Chairman, Federal Nursing Council, Brazil \\ ${ }^{4}$ Communication Advisor, Federal Nursing Council, Brazil}

Correspondence: David Lopes Neto, Manaus School of Nursing, Federal University of Amazonas, Brazil,

Email davidnetto@uol.com.br

Received: May 16, 2017 | Published: June 07, 2017

\section{Background}

The e-learning method, an internet-based learning through a computer is also described by multiple other terms: web-based learning, online/distance learning and computer-assisted training are just a few of them. This method uses information and communication technologies to teach people that may live in remote locations ${ }^{1}$ as a new innovative methodology. ${ }^{2}$

In the context of innovative education of the twenty-first century, the e-learning is establishing itself as an effective technological tool in the continuing education for health professionals with potential access to information regardless of time and physical space to update content studies.
According to the UK National Health Service, the e-learning in nursing has been used in continuing education of nurses, technicians and nursing auxiliaries searching for professional update, improvements and development of good clinical practices supported by scientific evidence. The method is considerate an essential and effective component for the continuing education of practioners. ${ }^{3}$

A study conducted at the St. Catherine University, USA, on the effectiveness and interactivity of distance learning in nursing, revealed that e-learning is an effective way to meet the needs of different students as well as an important component of a new style in promoting education through information technology to improve teaching and learning in and out of classrooms making students active subjects of their own learning helping them to practice nursing in new forms. ${ }^{4}$ 
Under the Federal and Regional Nursing Councils' structure, investments in technical and scientific fields have always been a concern. In special considering that to supervise and safeguard nurses and society is a Regional Nursing Council purposive activity. However in Brazil, a country of continental dimensions, the challenges lay on geographical, financial and logistical constraints to gather all nursing classes - which today, aggregate over 2 million professionals. The situation has made the Nursing Council build more effective strategies to meet a significant number of nursing practitioners with training courses and this was only possible through distance learning. The Proficiencia Program had the purpose of offering nursing practitioners training and development short courses that were based on continuing education and free of charge. The courses also needed to be undertaken remotely (via computer and internet), of practical content, spreading information, allowing individualized access as well as being an ongoing and flexible learning method, ${ }^{5}$ given that the communication through the internet connectivity and allows quick access and sharing of information. ${ }^{6}$ This study aimed to evaluate the effectiveness of the Proficiencia Program with the usability of the e-learning Jornada Platform for Brazilian nursing practitioners of continuing education.

\section{Methodology}

\section{Design}

Documentary research and evaluation in nursing education based in e-learning method. An online survey link with questions focused on Proficiência Program was emailed to nursing professionals. Evaluative research of online database held by the Brazilian Federal Nursing Council regarding Phase V's Assessment System of the Proficiencia Program in e-learning by the Virtual Learning Environment (VLE). Research was undertaken in 2013 and its central subjects were: Government Actions in Public Health Policies and Attention to Women's Health: foundations of nursing care.

\section{Sample and setting}

The sample population was 10.942 nursing professionals with registration in your state Regional Nursing Council who responded to the questionnaire on line. Research sources were constituted from the following databases: course's pedagogical project, study units summary, web pages, and users' ratings on the Proficiencia Program.

\section{Data collection}

Data was collected from the Jornada Platform e-learning+Learning Manager System's database and the evaluation process followed four stages proposed by Lecomte: ${ }^{7}$ initial findings, situation analysis, comparison (system model vs. system portrait) and improvements proposal. Data were collected during November-December 2013.

\section{Data analysis}

Analysis included frequency statistics and descriptive data for survey questions and content analysis.

\section{Ethical considerations}

Brazilian Federal Nursing Council spoiled this research.

\section{Results and discussion}

\section{Stage I-Initial findings}

At this first stage, it was found great acceptability of the Proficiencia Program by all nursing practitioners' categories. By undertaking courses, users have shown discipline and commitment, which is evidenced by the large number of graduates.

Among the users, it was found that accessibility to study was fundamental course attractiveness and maintenance. Freedom to determine time and place of studies and evaluating tests, the minimum requirements to access, the cost free elements of the courses added to the monitoring quality, that have helped in managing the studies, are all highlighted as significant and determinants to program user loyalty.

As for tutors involvement and professional assistance received, $97.4 \%$ of users responded that service was excellent/good, confirming the effectiveness of the educational web system used by the e-learning contractor company for the program operationalization. The service channels were considered effective as well as the technological resources used for student support (e-mail platform, phone and online chat). Emphasizing tutor-user relationship ${ }^{8}$ studies have showed that online education employs pedagogical assumptions from collaborative or cooperative learning with encouragement of student participation, information exchange relationship and experiences that provide meaningful learning. Thus, it was observed that the Proficiencia Program had the power to reorganize time and space, easing the need for physical presence and providing the professional, as a student, the balance between time, work and study. The tutor has the function to establish interaction, sensitization and mobilization of the group members under his mentorship, and to enable the development of technological capacities of the student ${ }^{9}$

\section{Stage 2-Situation analysis}

The use of the Jornada Platform and the Proficiencia Program by nursing practitioners through the Virtual Learning Environment (VLE), enabled online and interactive communication with the coordination team, tutors and mentors. Communication was available by e-mail, online chat and telephone. The studies were conducted in the e-learning modality. The system allowed the following browsers: Internet Explorer (version 7.0 or higher), Mozilla Firefox3.0 (or higher), Safari and Google Chrome. About navigability, the requirement was broadband connection (ADSL or similar). The best performance was obtained with a $600 / \mathrm{Kbps}$ upper connection. In this manner, the platform has provided the Proficiencia Program student and user an intuitive and organized navigation, with a clean and easy layout to handle.

\section{Stage 3 -Comparison: System model vs. system portrait}

The Jornada Platform+Learning Management System (LMS) provided online classrooms enriching student experience and creating interactivity in a virtual environment, these classrooms were available and divided per course and curricular subjects. The Learning Management System is a software package that manages and delivers learning content and resources to students. ${ }^{10} \mathrm{LMS}$ is a model has the following advantages: reduced costs in professional training, course availability $24 / 7$ with accessibility from any location; qualitative expert skills increase and personnel cost reductions for the companies and institutions to which these professionals are bound.

In content organization, the e-learning platform developed courses for the online distance model framed in themed groups and presented by studies units, which were composed of texts, videos, audios, links to third party websites, explanatory notes, photos, animations, charts, graphs and figures. 
As for interactivity, was confirmed good intercommunication between users, the coordination team, tutors and mentors. This was held in the Virtual Learning Environment (VLE) and has provided multiple interrelations: user/tutor, user/content, user/user, user/ environment, user/service and user/knowledge. It was found that the set of features designed for storage, distribution and management of course content, proceeded in a progressive, interactive and satisfactorily manner. ${ }^{11}$

For studies and exams, students could use operating systems (Mac OS, Windows and Linux) with audio devices, speakers or headphones. As for browsers, free access was possible through Internet Explorer (version 9.0 or higher), Mozilla Firefox 3.0 (or higher), Safari and Google Chrome, emphasizing that variations between them showed no loss in visualize images, illustrations and animations, the last two could run on Windows Media Player and Adobe Flash Player. About navigability, it was considered satisfactory using broadband connection (ADSL or similar) with speed from $600 \mathrm{Kbps}$. Each $30-$ hour course Table 1 had expert elaborated contents and subjects range raised from three situations: program coordinating team selection, field research-of which nursing practitioners themselves showed the need of such, market demand identified by the Federal Nursing Council.

Table I Course offering description by professional nursing category

\begin{tabular}{|c|c|c|c|}
\hline Number & Nurses & $\begin{array}{l}\text { Nursing technicians and } \\
\text { auxiliaries }\end{array}$ & 30 hours workload courses \\
\hline I & $\sqrt{ }$ & & Government actions in public health policies \\
\hline 2 & & $\sqrt{ }$ & \\
\hline 3 & $\sqrt{ }$ & & Patients' Aging associated alterations and interventions \\
\hline 4 & & $\sqrt{ }$ & \\
\hline 5 & $\sqrt{ }$ & & Patient's' Emotional and behavioral disorders in clinic \\
\hline 6 & & $\sqrt{ }$ & \\
\hline 7 & $\sqrt{ }$ & & Attention to women's health: foundations of nursing care \\
\hline 8 & & $\sqrt{ }$ & \\
\hline 9 & $\sqrt{ }$ & & $\begin{array}{l}\text { Nursing actions in preventing and controlling hospital infections: } \\
\text { fundamental aspects }\end{array}$ \\
\hline 10 & & $\sqrt{ }$ & \\
\hline II & $\sqrt{ }$ & & Caring for women in reproductive cycle: foundations of nursing care \\
\hline 12 & & $\sqrt{ }$ & \\
\hline 13 & $\sqrt{ }$ & & Aggravation and recrudescence of (re) emerging diseases in Brazil. \\
\hline 14 & & $\sqrt{ }$ & \\
\hline 15 & $\sqrt{ }$ & & Pain management in children: a nursing care \\
\hline 16 & & $\sqrt{ }$ & \\
\hline 17 & $\sqrt{ }$ & & Ethical implications in nursing and bioethics \\
\hline 18 & & $\sqrt{ }$ & \\
\hline 19 & $\sqrt{ }$ & & Intravenous therapy: quality assistance in nursing practices \\
\hline 20 & & $\sqrt{ }$ & \\
\hline 21 & $\sqrt{ }$ & & $\begin{array}{l}\text { Immunology and the national immunization program (Brazil): nursing performance } \\
\text { strategies }\end{array}$ \\
\hline 22 & & $\sqrt{ }$ & \\
\hline 23 & $\sqrt{ }$ & & Chemotherapy: updating nurses' knowledge \\
\hline
\end{tabular}

Source; COFEN, 2013.

$\sqrt{ } *$ Not available for nursing auxiliaries.

Courses have syllabus divided and organized in major subjects (between 3 and 6), called Núcleos Temáticos (NT). Each NT begins with a subject presentation video, lasting about 2-4 minutes. Didactic material went through a strict quality control carried out by the contractor company, which holds an ISO 9001/2008 certification under the scope of "Online Distance Education Services operationalization". The dialogicity shown through the tutor-student relationship has voiced a consistent positive reaction phenomenon, where teaching materials were the link to this proxemics and interactive relationship. 
Regarding the content covered in the courses-99.1\% of users responded that they thought they were Excellent/Good. Approval of the curricular components proved that the course selection of topics were appropriate and met participants' knowledge demands and expectations. At the same time noticing the programmatic advantage in extensive nursing areas covered. All of this within the national curricular guidelines, market demands and health care social needs.

The materials were made available in the form of texts with external links, further reading through access to hypertext, that value is also the dialogue language. In the complementary teaching material, audiovisual resources, in the form of illustrations and animations, make the Virtual Learning Environment (VLE) interactive, dynamic and attractive to students for allowing him to accessibility to scientific knowledge through reading, audio, image and video, sizing study time and examination for two hours. Thus, the balance between the texts, audiovisual resources, animations, voiceovers and illustrations, composed a delightful study of rhythm, prioritizing the rest of cognitive functions, each learning block and a pleasant reaction from the user.

Still as regarding to teaching resources, $96.4 \%$ of users have approved the content format. Similarly, the perception of the layout and distribution of the content contributed to the perception of the courses teaching quality. The examining system adopted by the Proficiencia Program was considered by $98.1 \%$ of users as Excellent/ Good, which demonstrated the effectiveness of the program. From this perspective, the examining system used led users to an effective learning, permeated by a process of continuous and effective monitoring by the tutor responsible for the group.

In the evaluation of the studies platform functionality, $98.3 \%$ of users have attributed Excellent/Good. This result inferred that the platform was an effective tool in achieving nursing professional improvement. In Brazil, the Jornada Platform is a differential in e-learning, besides having the Ministry of Education and Educational Technology recognition. The approval came from the use of simple and intuitive interface and factors such as usability and navigation platform, which facilitated access to studies, allowing the user autonomy in web-based learning process with the use of a computer at any time day, with reports that might be issued in real time.

The learning evaluation, of training type based on computer usage, produces effectiveness in learning outcome, leading users of e-learning educational technology to positive attitudes towards learning. This allows the user to: audit their knowledge and skills acquired as the course progresses and to conduct comments and discussions in virtual classrooms and in groups, in order to get instant feedback and as useful object to scientific and technical issues related to nursing. ${ }^{12} \mathrm{~A}$ systematic review assessed the effectiveness of distance education for nursing students and employed nurses showed that distance learning produces equivalent or better effects than traditional pedagogy. ${ }^{13}$

Regarding to users motivation to pursue courses on the Proficiencia Program, the data stated that $45 \%$ of them responded to have sought the course because of the content covered, $17 \%$ related to the teaching methodology, $15.9 \%$ because of the study platform, $5 \%$ tutor support and 16\% listed all options. With these findings, it was observed that the content addressed satisfied the expectations of most users, so as to bring them to course completion. To assess e-learning service satisfaction, including program recommendation (professional, friend), users stated that Proficiencia Program is a valid and meaningful consideration from the Federal and Regionals Nursing Council for nursing practitioners, considering that $99.9 \%$ of users recommend and acknowledge the e-learning Program as a tool linked to nursing continuing education.

The program's examining/assessment system was the assessment process model through partial and final exercises, undertaken online with questions extracted from an examination bank, prepared by the teacher-author. For each Unidades de Estudos (UE), the teacherauthor produced a minimum of 4 questions that allowed assessing the UE. However the exam consisted of 3 questions, each with four alternative answers and only one correct. Thus, the assessment process model is one of the strongest pillars of innovation and change in distance education, especially to the extent that sets goals for students and teachers-tutors. Highlighting that successful distance education students depend on deadlines and assessing activities to direct their learning efforts. On the other hand, the teacher-tutors become efficient to use innovative assessment tools to lead students to motivation, and thereby participate successfully in learning activities. ${ }^{14}$

Courses assessments were online and had a 45 days (an approximately 4 hours and 30 minutes per week commitment) completion deadline, which demonstrated interest and students approval.

\section{Stage 4 -Improvements proposal}

A possibility to continue to offer professional e-learning courses is one path to be pursued by the Federal Nursing Council. In order to carry on with the continuing education there must be processes updates and content complementation of the 24 existing courses, extension of the course length from 30 to 40 hours; new courses development in subjects that address Brazilian health and nursing work reality; increasing the number of vacancies exclusively for online distance education; inclusion of final reports and all courses contents, with updates that have been effected during the period of the offer of vacancies, converted to the standard SCORM (Sharable Content Object Reference Model). SCORM is an aggregation model personalized learning infrastructure so dynamic with the use of reusable learning objects. ${ }^{15}$

\section{Implications for nursing and health policy}

E-learning strategies are needed to create opportunities nursing professionals who live and work in remote areas to study and improve themselves. E-learning programs are flexible on the platform, scheduling module, study methods, accessibility, usability and support, usability and support. Training program of theoretical skill assist in the improvement of nursing care quality. Nursing training policies received large contribution as a result of the program organization and construction.

\section{Conclusion}

The Jornada Platform provided significant learning for the nursing practitioners with increased knowledge and the ability to develop safer nursing practices through behavior for the individual and collective work that the nursing profession requires. The pedagogical model of virtual teaching-learning environment allowed the nursing professional and the Federal Nursing Council to reach heir respective objectives with significant effects on nursing practitioners performance and working environment. The development of distance learning services offered by Proficiência Program was congruent with 
the purpose of the Federal Nursing Council to provide professionals an educational platform through information and communication technology that produces lifelong learning without time and space constraints, especially at zero cost to these professionals. Being recognized as relevant for training continuity to a career in nursing, the program contributed to professionals upgrading by allowing students to correct theoretical faults through knowledge consolidation and ideas in order to apply safer professional practices. It is noticeable the increased use of e-learning in training health professionals. ${ }^{16}$

The study, by focusing on continuing education nursing training program, merely describes the database information about the graduated users' evaluation of the Proficiência Program courses. New qualitative research with tutors, users and computer engineers would contribute to understand their perceptions and the technological dimensions of the nursing continuing education e-learning process. New information may be effective to further unveil the perception of nursing professionals who used this information and communication technology tool to update and improve their knowledge and practices.

\section{Acknowledgements}

None.

\section{Conflict of interest}

The author declares no conflict of interest.

\section{References}

1. Ruiz JG, Mintzer MJ, Leipzig RM. The impact of E-learning in medical education. Academic medicine. Journal of the Association of American Medical Colleges. 2006;81(3):207-212.

2. Nagunwa TP, Lwoga ET. Developing an eLearning strategy to implement medical competency based curricula: Experiences from Muhimbili University of Health and Allied Sciences; 2012. p. 1-6.

3. Childs S, Blenkinsopp E, Hall A, et al. Effective e-learning for health professionals and students--barriers and their solutions. A systematic review of the literature--findings from the HeXL project. Health Info Libr J supply. 2005;2:20-32.

4. Nicholson EA. E-learning in nursing: the effectiveness of interactivity. Antonian Scholars Honors Program; 2012.
5. Macêdo NB de, Albuquerque PC de, Medeiros KR de. The challenge of implementing continuing education in health education management. Trabalho, Educação e Saúde. 2014;12(2):379-401.

6. Xelegati R, Évora YDM. Development of a Virtual Learning Environment addressing adverse events in nursing. Revista Latino-Americana De Enfermagem. 2011;19(5):1181-1187.

7. Lecomte R, Rutman L. Introduction aux méthodes de recherche évaluative. Québec: Presses de l'Université Laval; 1982.

8. Rodrigues R de, Peres. Panorama brasileiro do ensino de Enfermagem On-line. Revista da Escola de Enfermagem da USP. 2008;42(2):298304.

9. Prado C, Christiane Pereira MC, Tania Oliveira, et al. Espaço virtual de um grupo de pesquisa: o olhar dos tutores. Revista da Escola de Enfermagem da USP. 2012;46(1):246-251.

10. Awang NB, Darus MYB. Evaluation of an Open Source Learning Management System: Claroline. Procedia - Social and Behavioral Sciences. 2012;67:416-426.

11. Prado C, Luiz Carlos Santiago, Jaqueline Alcântara Marcelino, et al. Ambiente virtual de aprendizagem no ensino de Enfermagem: relato de experiência. Revista Brasileira de Enfermagem. 2012;65(5):862-866.

12. Peat M, Franklin S. Supporting student learning: the use of computerbased formative assessment modules. British Journal of Educational Technology. 2002;33(5):515-523.

13. Du S, Liu Z, Liu S, et al. Web-based distance learning for nurse education: a systematic review: Web-based distance learning for nursing education. Int Nurs Rev. 2013;60(2):167-177.

14. Gulínska H, Bartoszewicz M. The effects of using the share point platform in teaching science students and teachers. In: Zuljan MV, Vogrinc J editors. Facilitates effective student learning through teacher research and innovation. Ljubljana, Slovenia: Faculty of Education; 2010.

15. Zaba N, Mohd Nor Mamat, Mohd Ali Mohd Isa, Azlan Abd Aziz, Prasanna Ramakrisnan, et al. (2012) A Comparative Study Among Selected Global Standards: i-Learn as A Case Study. Procedia - Social and Behavioral Sciences. 2012;67:476-483.

16. Dror I, Schmidt P, O connor L. A cognitive perspective on technology enhanced learning in medical training: great opportunities, pitfalls and challenges. Med Teach. 2011;33(4):291-296. 